\title{
Effects of proton pump inhibitors and electrolyte disturbances on arrhythmias
}

This article was published in the following Dove Press journal:

International Journal of General Medicine

27 June 2013

Number of times this article has been viewed

\section{Elie El-Charabaty \\ Chadi Saifan \\ Mokhtar Abdallah \\ Ali Naboush \\ Daniel Glass \\ Georges Azzi \\ Yorg Azzi \\ Ahsan Khan \\ Hassan Baydoun \\ Chetana Rondla \\ Ninad Parekh \\ Suzanne El-Sayegh}

Department of Medicine, Staten Island University Hospital, Staten Island, NY, USA
Correspondence: Chadi Saifan Division of Nephrology, Staten Island University Hospital, 475 Seaview Avenue, Staten Island, NY 10305, USA

Email chadisaifan@hotmail.com
Abstract: Several case reports have been written regarding the relationship between the use of proton pump inhibitors (PPI) and hypomagnesemia. Some of these reported cases have electrocardiogram abnormalities where electrolytes deficiencies were the contributing factor for these events. This study investigates the correlation between different arrhythmias and the use of PPI and hypomagnesaemia incidence. Four-hundred and twenty-one patients admitted to the critical care unit with unstable angina, non-ST elevation myocardial infarction, and ST-elevation myocardial infarction were included in this study. One-hundred and eighty-four patients (43.8\%) received PPI and 237 patients (51.16\%) did not, magnesium levels were low $(<1.8 \mathrm{mg} / \mathrm{dL})$ in 95 patients $(22.5 \%)$, and 167 patients $(39.6 \%)$ developed arrhythmias. The $P$-values for the regression coefficient association for the use of PPI and the level of magnesium were $P=1.31 \mathrm{e}^{-29}$ and $P=8 \mathrm{e}^{-102}$, respectively. The $P$-values indicate that there is a statistically significant association between the PPI use, magnesium levels, and the occurrence of cardiovascular events, with a strong correlation factor of 0.817 . Patients receiving PPIs should be followed closely for magnesium deficiency, especially if they experience acute cardiovascular events, because this may contribute to worsening arrhythmias and further complications.

Keywords: electrolyte disturbances, medications side effects, cardiac arrhythmias

\section{Introduction}

Proton pump inhibitors (PPIs) are widely used therapeutic agents with more than 119 million filled prescriptions in the USA in $2009 .{ }^{1}$ They have been associated with a wide variety of side effects including renal failure, ${ }^{2,3}$ respiratory infections, ${ }^{4}$ Clostridium difficile colitis, ${ }^{5}$ and hip fractures. ${ }^{6}$ There have been several case reports and case series' of proton pump related hypomagnesemia with a wide array of symptoms, including cardiac arrhythmias and seizures. ${ }^{7-18}$

Magnesium is the second most common intracellular cation and is involved in a wide range of cellular functions, including protein synthesis, enzymatic reactions, and the regulation of ion channels. Significantly low serum magnesium levels have been associated with bradycardia, hypotension, seizures, tetany, and death. ${ }^{19,21}$ Even mild hypomagnesemia has been correlated with cardiovascular and total mortality. ${ }^{22}$ Despite a recent retrospective study demonstrating an association between hypomagnesaemia and PPI use in patients on diuretics, there is no large scale study on PPI use and the incidence of cardiac arrhythmias. To address this question, we examined the association between the use of PPI, serum magnesium levels, and the incidence of cardiac arrhythmia in a large group of patients admitted to the intensive care unit (ICU) with an acute coronary syndrome and subsequently started on a PPI. 


\section{Methods}

This study included patients admitted to a tertiary care hospital to the ICU or critical care unit (CCU) with a diagnosis of unstable angina, ST elevation myocardial infarction (STEMI), non-STEMI (NSTEMI), between 2007 and 2012 started on PPI during their hospital stay. This was a retrospective chart review study. Analysis involved checking occurrence of arrhythmias such as ventricular fibrillation, ventricular tachycardia, nonsustained ventricular tachycardia, atrial fibrillation, and atrial tachycardia. Potassium and magnesium blood levels were checked. Electrocardiograms with associated arrhythmias were reviewed. Any ICU or CCU patients older than 18 years of age diagnosed on admission with unstable angina, NSTEMI, or STEMI, were included in this study. Pregnant women, cognitively impaired patients, patients less than 18 years of age, and patients diagnosed with chronic atrial fibrillation on admission were excluded.

\section{Results}

Four-hundred and twenty-one patients admitted to the CCU with unstable angina, NSTEMI, or STEMI were included in this study. One-hundred and eighty-four patients (43.8\%) received PPI and 237 patients $(51.16 \%)$ did not. The normal level of magnesium is $1.8-2.4 \mathrm{mg} / \mathrm{dL}$ and a normal potassium level is $3.5-5 \mathrm{mmol} / \mathrm{L}$. Of our sample, $81.7 \%$ of patients were older than 55, 95.2\% had hypertension, 37.5\% had diabetes mellitus type II, $47 \%$ had chronic kidney disease (glomerular filtration rate $<60$ ), $71.2 \%$ had NSTEMI, and $25 \%$ had STEMI. PPI were prescribed during the hospital admission as either part of the gastrointestinal prophylaxis protocol for patients admitted to CCU (171 patients) or because they had peptic ulcer disease (13 patients).

Low magnesium levels $(<1.8 \mathrm{mg} / \mathrm{dL})$ were present in 95 patients $(22.5 \%)$ and 167 patients $(39.6 \%)$ developed arrhythmias. The $P$-values for the tests of significance determined using regression coefficient association for the use of PPI and the level of magnesium were $P=1.31 \mathrm{e}^{-29}$ and $P=8 \mathrm{e}^{-102}$, respectively, indicating that there is a statistically significant association between PPI use, the level of magnesium, and the occurrence of cardiovascular events, with a strong correlation factor of 0.817 .

\section{Discussion}

In this large, hospital-based cross-sectional study, PPI exposure during hospitalization was correlated with lower serum magnesium concentrations and cardiac arrhythmias.

Although the risk of hypomagnesemia and the incidence of cardiac arrhythmias has been suggested by smaller observational studies and case reports, this study is the first to our knowledge to provide an analysis between PPI use and magnesium concentrations and correlation with cardiac arrhythmias in a large sample, and supports the notion that PPI use may lead to hypomagnesemia and arrhythmias in susceptible individuals.

The pathophysiology of PPI-induced hypomagnesemia is still not certain. Magnesium homeostasis depends on the balance between renal excretion and intestinal absorption. Intestinal absorption occurs through two major pathways: active and passive. Active transcellular transport across the apical lumen occurs via the channel transient receptor potential melastatin $6 .{ }^{24}$ Tight junction proteins claudin- 16 and claudin-19 modulate passive movement down a concentration gradient which occurs paracellularly and is thought to be the major route of magnesium absorption. ${ }^{25}$ Tubular reclamation in the proximal tubule and thick ascending limb via paracellular absorption accounts for most renal excretion, ${ }^{26}$ with some active absorption in the distal convoluted tubule. ${ }^{27}$

New scientific data suggest that PPIs can cause hypomagnesaemia by inhibiting intestinal absorption and not by increasing renal wasting. ${ }^{23}$ In a case series of hypomagnesemic patients on PPI therapy, ${ }^{10}$ urine magnesium levels were appropriately low. Intravenous magnesium rapidly corrected serum concentrations, but oral magnesium did not, ${ }^{7,9}$ except in one case. ${ }^{11}$ Cell culture data suggests that PPIs disrupt passive magnesium absorption across intestinal epithelial cells. ${ }^{28}$

Table I The total number of patients (42I) separated by those who received PPIs (184) and those who did not (237)

\begin{tabular}{|c|c|c|c|c|c|c|c|c|}
\hline \multirow[b]{3}{*}{$\mathrm{CV}$} & \multicolumn{4}{|c|}{ PPI (184) } & \multicolumn{4}{|c|}{ No PPI (237) } \\
\hline & \multicolumn{2}{|c|}{ Low magnesium (47) } & \multicolumn{2}{|c|}{ No low magnesium (137) } & \multicolumn{2}{|c|}{ Low magnesium (48) } & \multicolumn{2}{|c|}{ No low magnesium (189) } \\
\hline & $(+15)$ & $(-32)$ & $(+32)$ & $(-105)$ & $(+25)$ & $(-23)$ & $(+59)$ & $(-130)$ \\
\hline
\end{tabular}

Notes: The second row shows the number of patients who developed low magnesium levels for both groups. The third row shows the number of patients who developed (or not) cardiac arrhythmias. The numbers in brackets indicate the number of patients in that category.

Abbreviations: CV, cardiac arrhythmias; PPI, proton pump inhibitor. 
By irreversibly blocking the hydrogen/potassium adenosine triphosphatase enzyme, PPIs inhibit the secretion of the acidic hydrogen ${ }^{+}$ions into the gastric lumen. Studies on both animals and human showed expression of the hydrogen $\mathrm{n}^{+} /$potassium $^{+}$ ATPase enzyme in their myocardium, and ribonucleic acid (RNA) was isolated from heart muscle strips of patients with end stage heart disease undergoing heart transplantation..$^{29,30}$ Subsequent studies on the electrophysiological effects of PPI on the myocardial cells were conducted, and showed a dose dependent reduction in isometric and isotonic shortening of myocytes cells as a consequence of the impairment of calcium uptake by the sarcoplasmic reticulum, leading to intracellular increased calcium concentration. ${ }^{30}$ Since calcium concentration is an important factor in myocytes automaticity ${ }^{31}$ and since focal arrhythmias are usually secondary to increased automaticity, a case control study was conducted on 80 patients undergoing an electrophysiological study and found that there was a 4-fold increase in focal arrhythmias in the group of the 40 patients on PPI when compared to the control group not on PPI. ${ }^{32}$

There are several important limitations of our analysis. Given the observational nature of the study, causality cannot be established between PPI exposure and serum magnesium concentration and cardiac arrhythmias. In addition, as our sample is comprised of critically ill patients, generalization to the outpatient population is uncertain. Diuretic use has been proven to be associated with PPI-induced hypomagnesemia. Our research did not collect data on diuretic use and stratification by diuretic use may have demonstrated a greater effect. Therefore, well-controlled prospective studies are needed to clarify all the clinical issues related to the use of this widely prescribed class of medication.

\section{Disclosure}

The authors report no conflicts of interest in this work.

\section{References}

1. IMS Health INSP, Top Therapy Classes by United States Dispensed Presciptions, Data from 2007. Available at: http://www.imshealth. $\mathrm{com} / \mathrm{cds} / \mathrm{ims} /$ Global/Content/Corporate/Press\%20Room/Top-line $\% 20$ Market\%20Data/2009\%20Top-line\%20Market\%20Data/Top\%20Therapy\%20Classes\%20by\%20U.S.Sales.pdf. Accessed March 3, 2011.

2. Ray S, Delaney M, Muller AF. Proton pump inhibitors and acute interstitial nephritis. BMJ. 2010;341:c4412.

3. Sierra F, Suarez M, Rey M, Vela MF. Systematic review: Proton pump inhibitor-associated acute interstitial nephritis. Aliment Pharmacol Ther. 2007;26(4):545-553.

4. Herzig SJ, Howell MD, Ngo LH, Marcantonio ER. Acid-suppressive medication use and the risk for hospital-acquired pneumonia. JAMA. 2009;301(20):2120-2128
5. Howell MD, Novack V, Grgurich P, et al. Iatrogenic gastric acid suppression and the risk of nosocomial Clostridium difficile infection. Arch Intern Med. 2010;170(9):784-790.

6. Faulhaber GA, Furlanetto TW. Could magnesium depletion play a role on fracture risk in PPI users? Arch Intern Med. 2010;170(19):1776.

7. Epstein M, McGrath S, Law F. Proton-pump inhibitors and hypomagnesemic hypoparathyroidism. $N$ Engl J Med. 2006;355(17): 1834-1836.

8. Metz DC, Sostek MB, Ruszniewski P, Forsmark CE, Monyak J, Pisegna JR. Effects of esomeprazole on acid output in patients with Zollinger-Ellison syndrome or idiopathic gastric acid hypersecretion. Am J Gastroenterol. 2007;102(12):2648-2654.

9. Shabajee N, Lamb EJ, Sturgess I, Sumathipala RW. Omeprazole and refractory hypomagnesaemia. BMJ. 2008;337:a425.

10. Cundy T, Dissanayake A. Severe hypomagnesaemia in long-term users of proton-pump inhibitors. Clin Endocrinol (Oxf). 2008;69(2): 338-341.

11. Broeren MA, Geerdink EA, Vader HL, van den Wall Bake AW. Hypomagnesemia induced by several proton-pump inhibitors. Ann Intern Med. 2009;151(10):755-756.

12. Kuipers MT, Thang HD, Arntzenius AB. Hypomagnesaemia due to use of proton pump inhibitors - a review. Neth J Med. 2009;67(5):169-172.

13. Hoorn EJ, van der Hoek J, de Man RA, Kuipers EJ, Bolwerk C, Zietse R. A case series of proton pump inhibitor-induced hypomagnesemia. Am J Kidney Dis. 2010;56(1):112-116.

14. Regolisti G, Cabassi A, Parenti E, Maggiore U, Fiaccadori E. Severe hypomagnesemia during long-term treatment with a proton pump inhibitor. Am J Kidney Dis. 2010;56(1):168-174.

15. Mackay JD, Bladon PT. Hypomagnesaemia due to proton-pump inhibitor therapy: a clinical case series. QJM. 2010;103(6):387-395.

16. Cundy T, Mackay J. Proton pump inhibitors and severe hypomagnesaemia. Curr Opin Gastroenterol. 2011;27(2):180-185.

17. Quasdorff M, Mertens J, Dinter J, Steffen HM. Recurrent hypomagnesemia with proton-pump inhibitor rechallenge. Ann Intern Med. 2011;155(6):405-407.

18. Furlanetto TW, Faulhaber GA. Hypomagnesemia and proton pump inhibitors: below the tip of the iceberg. Arch Intern Med. 2011;171(15): 1391-1392.

19. Flink EB. Magnesium deficiency. Etiology and clinical spectrum. Acta Med Scand Suppl. 1981;647:125-137.

20. Vallee BL, Wacker WE, Ulmer DD. The magnesium-deficiency tetany syndrome in man. N Engl J Med. 1960;262:155-161.

21. Moore MJ, Flink EB. Magnesium deficiency as a cause of serious arrhythmias. Arch Intern Med. 1978;138(5):825-826.

22. Reffelmann $T$, Ittermann $T$, Dörr $M$, et al. Low serum magnesium concentrations predict cardiovascular and all-cause mortality. Atherosclerosis. 2011;219(1):280-284.

23. Danziger J, William JH, Scott DJ, et al. Proton-pump inhibitor use is associated with low serum magnesium concentrations. Kidney Int. 2013;83(4):692-699.

24. Schlingmann KP, Weber S, Peters M, et al. Hypomagnesemia with secondary hypocalcemia is caused by mutations in TRPM6, a new member of the TRPM gene family. Nat Genet. 2002;31(2): $166-170$.

25. Hou J, Renigunta A, Konrad M, et al. Claudin-16 and claudin-19 interact and form a cation-selective tight junction complex. $J$ Clin Invest. 2008;118(2):619-628.

26. Quamme GA. Control of magnesium transport in the thick ascending limb. Am J Physiol. 1989;256(2 Pt 2):F197-F210.

27. Dai LJ, Ritchie G, Kerstan D, Kang HS, Cole DE, Quamme GA. Magnesium transport in the renal distal convoluted tubule. Physiol Rev. 2001;81(1):51-84.

28. Thongon N, Krishnamra N. Omeprazole decreases magnesium transport across Caco-2 monolayers. World J Gastroenterol. 2011;17(12): $1574-1583$ 
29. Nagashima R, Tsuda Y, Maruyama T, Kanaya S, Fujino T, Niho Y. Possible evidence for transmembrane $\mathrm{K}(+)-\mathrm{H}+$ exchange system in guinea pig myocardium. Jpn Heart J. 1999;40(3):351-364.

30. Schillinger W, Teucher N, Sossalla S, et al. Negative inotropy of the gastric proton pump inhibitor pantoprazole in myocardium from humans and rabbits: evaluation of mechanisms. Circulation. 2007;116(1):57-66.
31. Mangoni ME, Nargeot J. Genesis and regulation of the heart automaticity. Physiol Rev. 2008;88(3):919-982.

32. Marcus GM. Proton Pump Inhibitors Associated With Focal Arrhythmias. 2010. Division of Cardiology, Electrophysiology Section, University of California, San Francisco, CA, USA. Available at http://www.innovationsincrm.com/cardiac-rhythm-management/2010/ december/29-proton-pump-inhibitors-focal-arrhythmias.

\section{Publish your work in this journal}

The International Journal of General Medicine is an international, peer-reviewed open-access journal that focuses on general and internal medicine, pathogenesis, epidemiology, diagnosis, monitoring and treatment protocols. The journal is characterized by the rapid reporting of reviews, original research and clinical studies across all disease areas.
A key focus is the elucidation of disease processes and management protocols resulting in improved outcomes for the patient.The manuscript management system is completely online and includes a very quick and fair peer-review system. Visit http://www.dovepress.com/ testimonials.php to read real quotes from published authors.

Submit your manuscript here: http://www.dovepress.com/international-journal-of-general-medicine-journal 